\title{
Uber Amsterdam: Gebruikers Uber-app, gemaakte trips en verdiensten 2016-2019
}

Citation for published version (APA):

Fouarge, D., \& Steens, S. (2020). Uber Amsterdam: Gebruikers Uber-app, gemaakte trips en verdiensten 2016-2019. ROA. ROA Fact Sheets No. 006 https://doi.org/10.26481/umarof.2020006

Document status and date:

Published: 17/09/2020

DOI:

10.26481/umarof.2020006

Document Version:

Publisher's PDF, also known as Version of record

\section{Please check the document version of this publication:}

- A submitted manuscript is the version of the article upon submission and before peer-review. There can be important differences between the submitted version and the official published version of record.

People interested in the research are advised to contact the author for the final version of the publication, or visit the DOI to the publisher's website.

- The final author version and the galley proof are versions of the publication after peer review.

- The final published version features the final layout of the paper including the volume, issue and page numbers.

Link to publication

\footnotetext{
General rights rights.

- You may freely distribute the URL identifying the publication in the public portal. please follow below link for the End User Agreement:

www.umlib.nl/taverne-license

Take down policy

If you believe that this document breaches copyright please contact us at:

repository@maastrichtuniversity.nl

providing details and we will investigate your claim.
}

Copyright and moral rights for the publications made accessible in the public portal are retained by the authors and/or other copyright owners and it is a condition of accessing publications that users recognise and abide by the legal requirements associated with these

- Users may download and print one copy of any publication from the public portal for the purpose of private study or research.

- You may not further distribute the material or use it for any profit-making activity or commercial gain

If the publication is distributed under the terms of Article $25 \mathrm{fa}$ of the Dutch Copyright Act, indicated by the "Taverne" license above, 


\section{Maastricht University $\$ \mathrm{ROA}$}

\section{Uber Amsterdam: \\ Gebruikers Uber-app, gemaakte trips en verdiensten 2016-2019}

Didier Fouarge

Sanne Steens

\section{ROA Factsheet}

ROA-F-2020/6

Researchcentrum voor Onderwijs en Arbeidsmarkt | ROA Research Centre For Education and the Labour Market / ROA 


\section{Uber Amsterdam: Gebruikers Uber-app, gemaakte trips en verdiensten 2016-2019 Factsheet
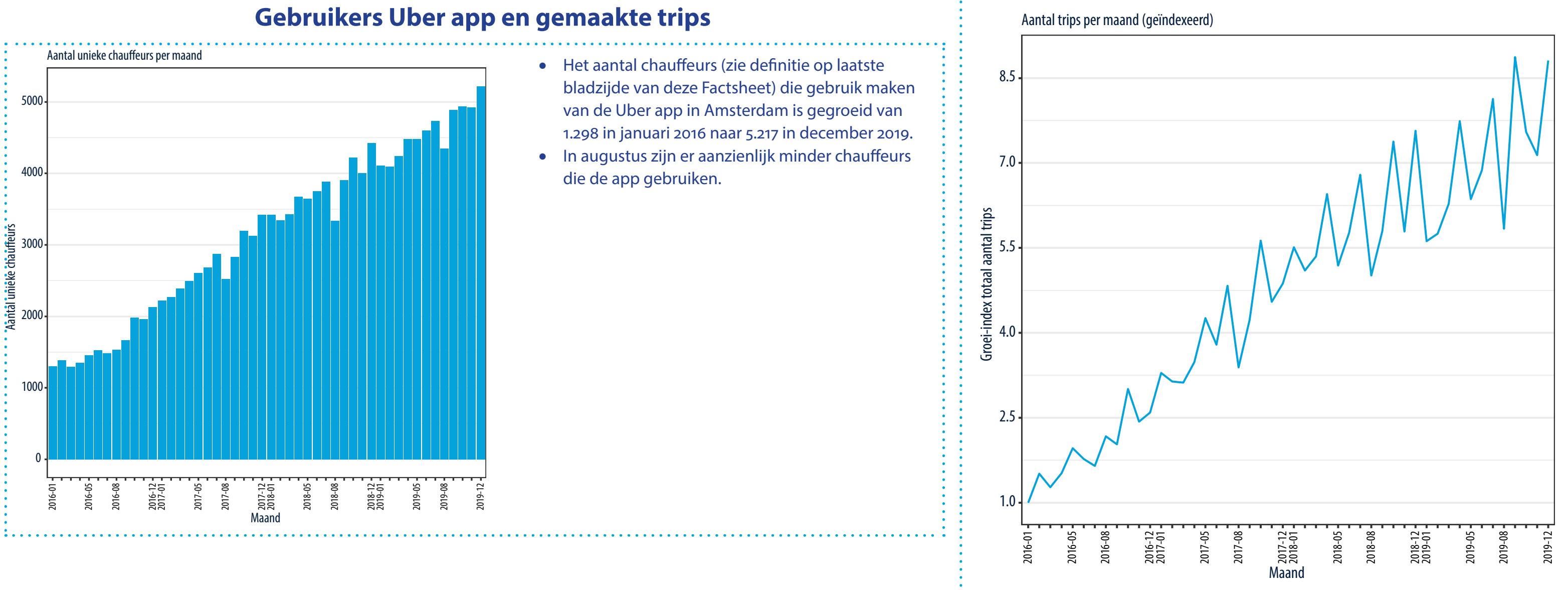

Het totale aantal trips per maand verzorgd door Uber $(X$, Black en Van) is in december 20198,8 keer hoger dan in januari 2016.

- De stijging gaat gepaard met grote: fluctuaties tussen de maanden: er worden meer trips verzorgd in de periode april/juli, minder trips in augustus en weer meer trips vanaf september/oktober De dip in het antal trips in augustus komt: in het anntaltips in augustus kom ? overeen met de dip in het aan

actieve chauffeurs.

Het totale aantal afgelegde kilometers door de chauffeurs over: al die trips is tussen 2016 en 2019 ruim verviervoudigd.

- De gemiddelde afstand per trip is gestegen van $8,1 \mathrm{~km}$ per trip in 2016 naar $9 \mathrm{~km}$ in 2019 


\section{Uber Amsterdam: Gebruikers Uber-app, gemaakte trips en verdiensten 2016-2019 Factsheet}

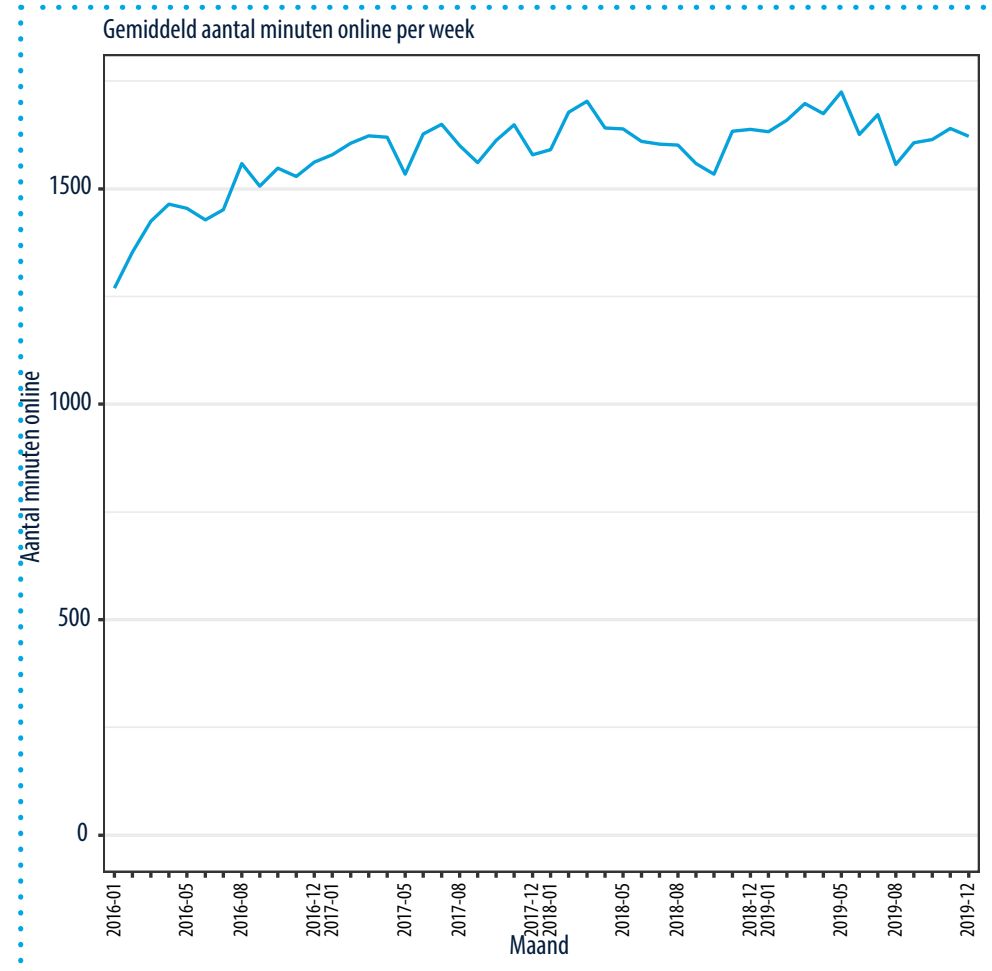

- De tijd die gebruikers gemiddeld genomen besteden op de app (tijd online; zie definitie op laatste bladzijde van deze Factsheet) is gestegen in de eerste maanden van 2016, om daarna relatie stabiel te blijven. Dit betekent dat de stijgende vraag van klanten opgevangen wordt door het stijgend aantal gebruikers van de Uber app.

De tijd die chauffeurs actief bezig zijn met ritten piekt in de zomer.

- In 2019 was een gebruiker per week gemiddeld 24 uur online, maar het gebruik verschilt aanzienlijk tussen chauffeurs (zie grafiek later in deze Factsheet).

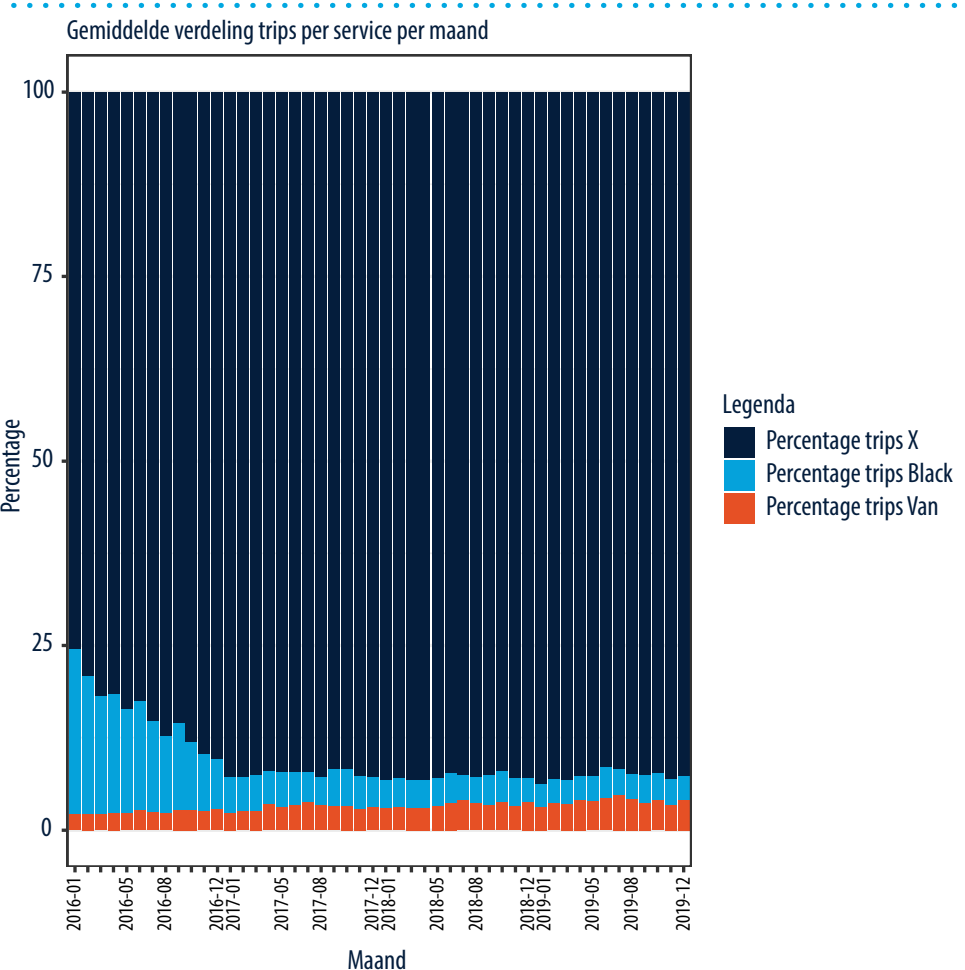

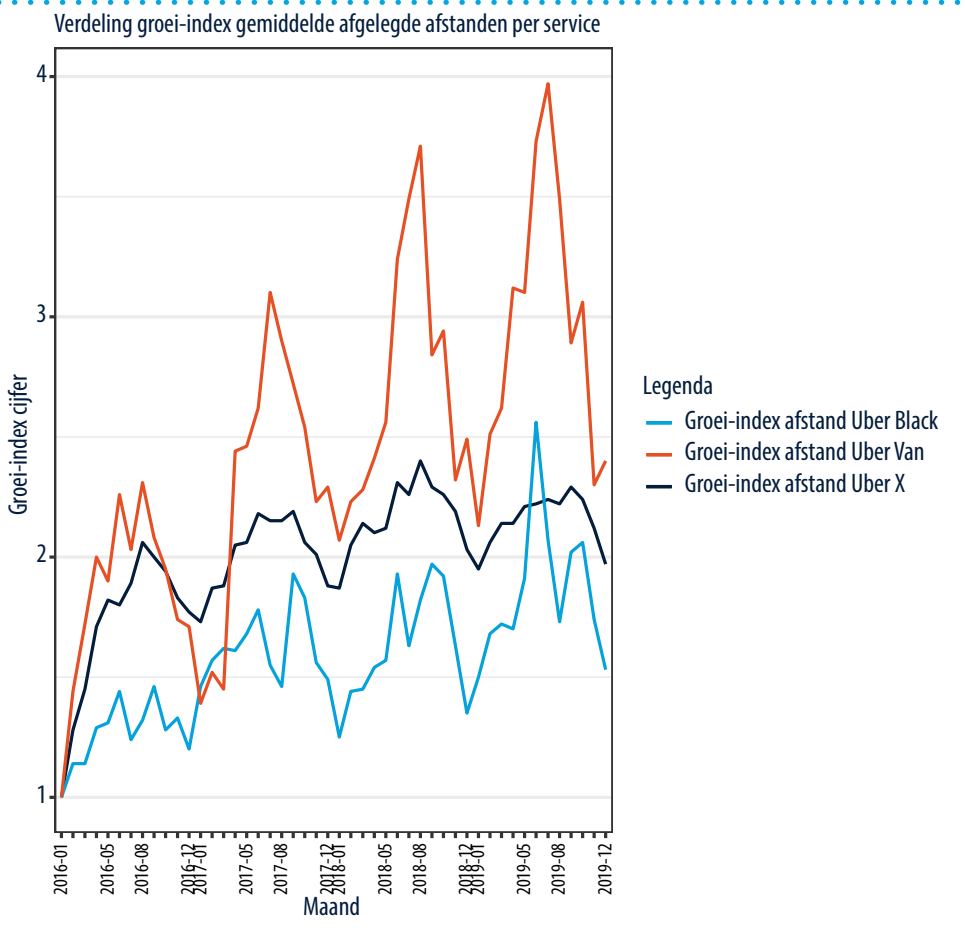

Het totaal aantal afgelegde kilometers per maand door de chauffeurs is vanaf januari 2016 to december 2019 ruim vertienvoudigd.

- In januari 2016 reed een chauffeur met Uber X-trips gemiddeld 202.57 kilometer per week voor Uber X, de chauffeurs die trips hebben verzorgd voor Uber Black, reden gemiddeld 104 kilometer voor deze legden gemiddeld 51 kilometer per week af voor Uber Van trips.

- In december 2019 was dit 399 kilometer voor Uber X, 159 voor Uber Black en 122 voor Uber Van.

- De gereden afstanden vertonen duidelijke

seizoens-fluctuaties. Er worden grotere afstanden afgelegd in de zomermaanden dan daarbuiten Deze fluctuaties zijn vooral duidelijk te zien bij Uber Van. Dit kan te maken hebben met het vervoer van vakantiegangers van en naar Schiphol, of dagtripjes naar het strand of omliggende steden : en dorpen.
- Uber verleent drie verschillende services in Amsterdam: Uber X (reguliere versie), Uber Black (luxere versie met betere auto's) en Uber Van (auto's die geschikt zijn voor grotere groepen).

- De meeste trips worden uitgevoerd door Uber X. Het gebruik van Uber Black is sterk afgenomen. In januari 2016 werden ruim $22 \%$ van alle trips verzorgd door Uber Black, aan het einde van dat jaar is dit nog maar $6,9 \%$, verder blijft het stabiel ussen de 3 en $5 \%$.

- Het gebruik van Uber Van stijgt marginaal van $2 \%$ tot maximaal $4,7 \%$ van alle trips. 


\section{Uber Amsterdam: Gebruikers Uber-app, gemaakte trips en verdiensten 2016-2019 Factsheet}

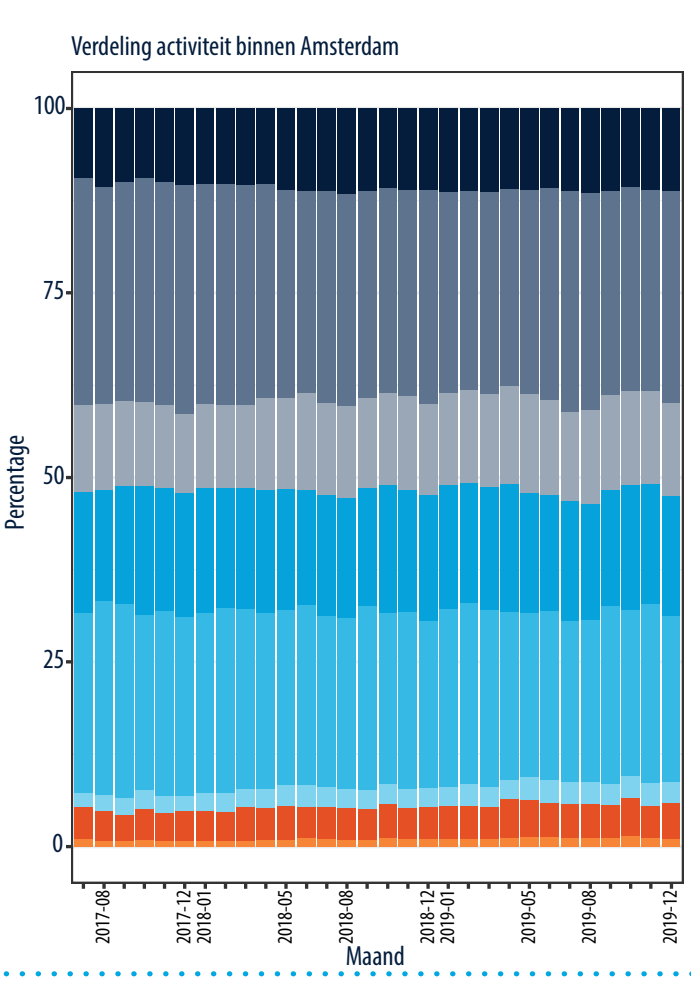

Perents

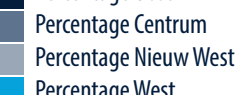

Percentage West
Percentage Zuid

Perentage Zuid 0ost
Perentage Noord
Percentage Westpoort

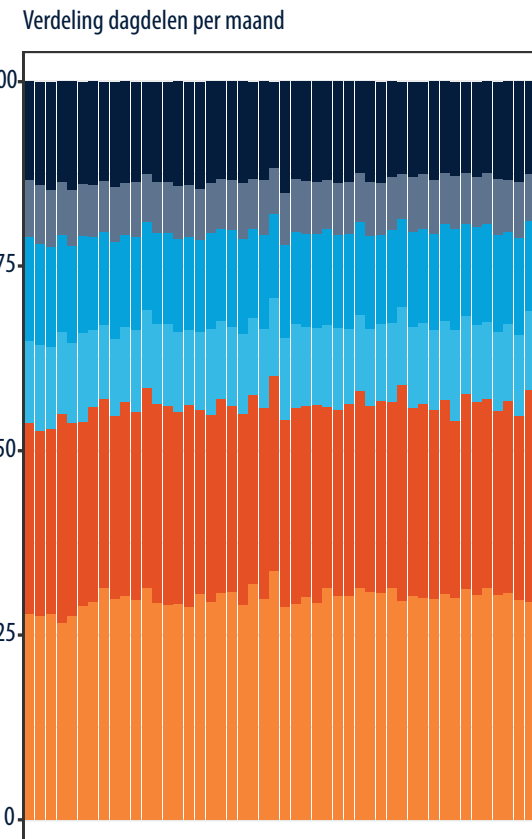

Legenda
Perentage weekdag vroege ochtend
Percentage weekdag late ochtend

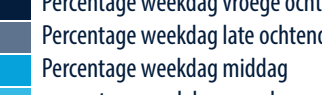

percentage weekdag avond
Percentage weekdag's nachs

Perentage weekdag's
Percentage weekend
- De locatie van de activiteit is vanaf juli 2017 beschikbaar.

- Voor de activiteit binnen Amsterdam komt app-activiteit in het Centrum (gemiddeld 28\%) en Zuid (gemiddeld $24 \%$ ) het vaakst voor Dit is mogelijk te verklaren door de locatie van de Zuidas mog Centrum reist.

ber-app zijn het minst vaak online in de wijken Westpoort (gemiddeld 0,8\%) en Zuid Oost (gemiddeld 2,5\%).

De verdeling over de wijken blijft gedurende de gehele periode redelijk stabiel.
- Uber diensten worden vaker afgenomen in sommige dagdelen dan in andere dagdelen. De meeste ritten worden gemaakt in het weekend en 's nachts doordeweeks. Een mogelijke verklaring is de verminderde beschikbaarheid van het openbaar vervoer.

- De verdeling van ritten over dagdelen blijft redelijk stabiel over de tijd. In december 2017 zien we een stijging in ritten in het weekend. En mogelije verklaring is dat kerstavond en oudjaarsavond beiden op een zondag waren

\section{Ratings en acceptance}

- Vrijwel elke chauffeur ontvangt minimaal 1 rating in hun tijd bij Uber

In slechts $2,2 \%$ van alle weken wordt er geen rating gegeven, in deze gevallen maakt de chauffeur zonder ontvangen rating gemiddeld slechts 2 trips via de Uber app in zo'n week.

- De gemiddelde rating per maand is vrij stabiel en stijgt langzaam van 4,7 in januari 2016 naar 4,9 in eind 2019.

- Gemiddeld over de gehele periode ontvangt een chauffeur een rating van 4,8. Hier zit weinig verschil in tussen chauffeurs: een kwart van de chauffeurs ontvangt een rating van 4,75 of minder en een kwart een rating van 4,9 of meer.

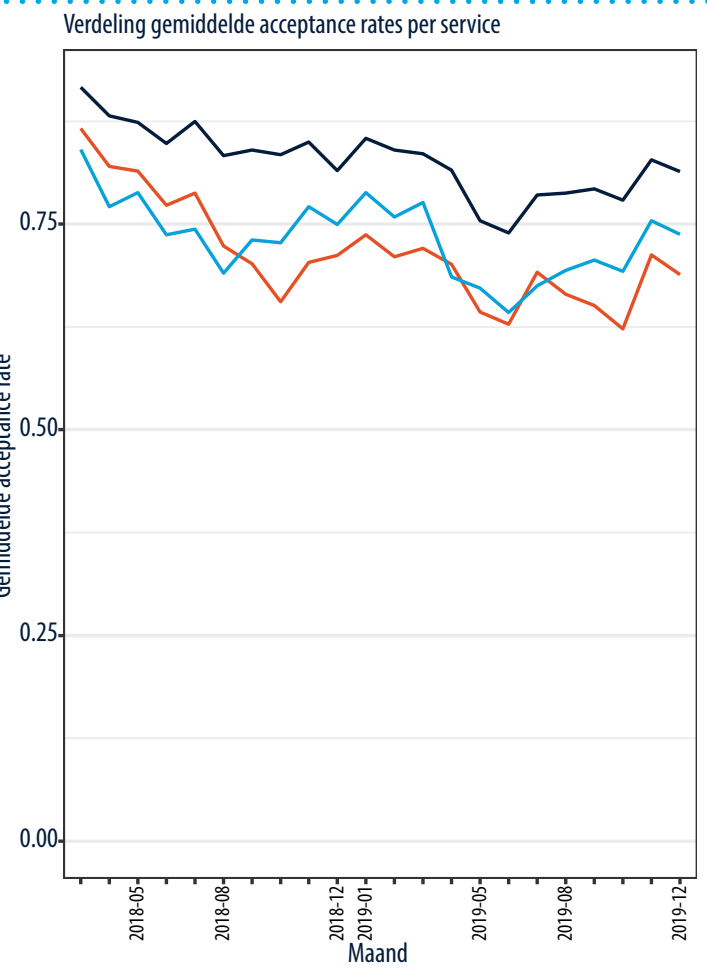

legenda

- Acceptance rate Blact

- Acceptance rate Var
- Acceptance rate $X$
De gemiddelde acceptance rates (zie definitie aa het einde van deze Factsheet) dalen voor elke service. Voor Uber $X$ schommelt dit tussen de 0,62 en 0,87 . Voor Uber Black is dit 0,74 en 0,92. Uber Van chauffeurs accepteren minimaal $64 \%$ en maximaal $84 \%$ van alle Van-trips. De acceptance rates voor Uber Black zijn hoger dan die van X en Van, dit kan mogelijk verklaard worden doordat de verdiensten voor trips voor Black hoger zijn dan vergelijkbare trips voor X of Van.

- De cancellation rates zijn het laagst voor Uber Black, die zijn maximaal 8,8\%, terwijl Uber $X$ maximaal $13,2 \%$ van de ritten cancelt en Uber Van maximaal $14,6 \%$.

- De surged trips (zie definitie aan het einde van deze Factsheet) hebben gemiddeld een 5\% hogere acceptance rate dan de trips die niet surged zijn. 


\section{Uber Amsterdam: Gebruikers Uber-app, gemaakte trips en verdiensten 2016-2019 Factsheet}

\section{Bruto verdiensten}

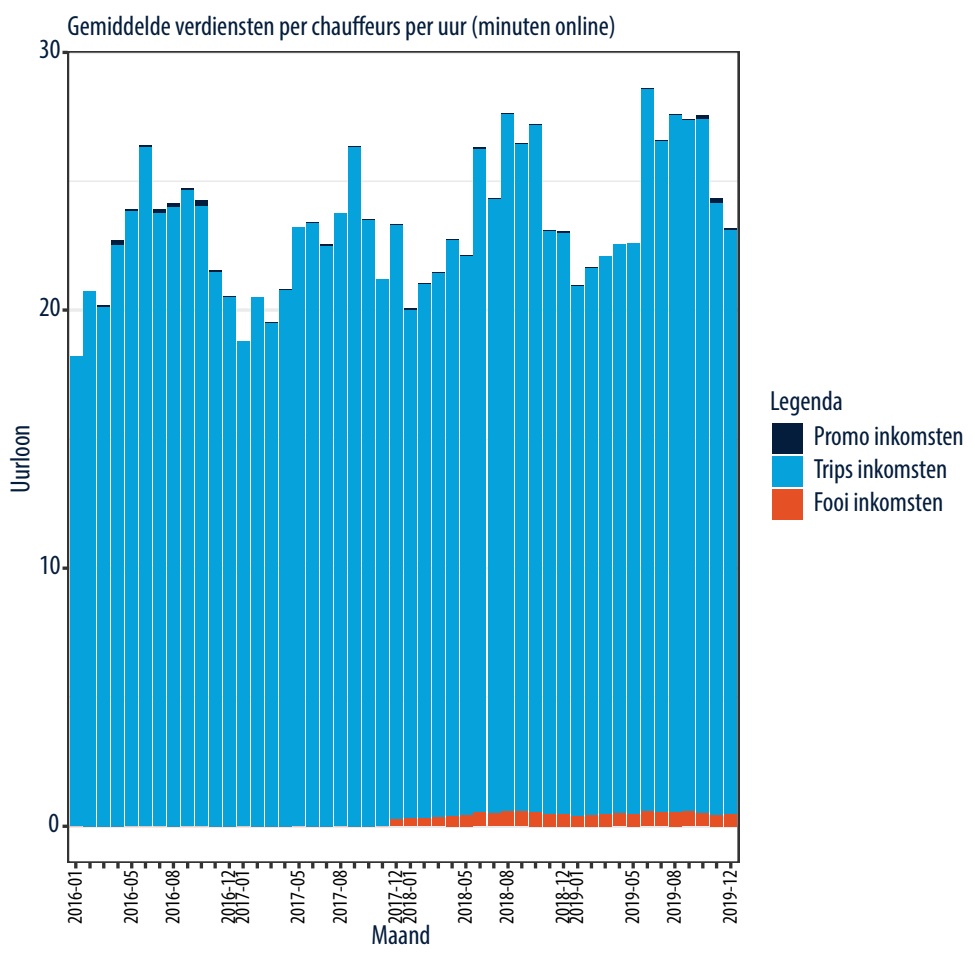

- Door de totale bruto verdiensten (uit trips, fooi en promo: zie definitie op laatste bladzijde van de Factsheet) te delen door de tijd dat chauffeurs onlinezinn kan een beeld wordengegeven var verdiensten per uur.

ters worden gereden met Uber

De bruto verdiensten van chauffeurs per uur waren gemiddeld $€ 22,62$ in 2016 en gemiddeld $€ 24,48$ in 2019.

Deze verdiensten per uur fluctueren over de maanden en zijn het hoogst in de zomer, wanneer de meeste ritten plaatsvinden.

- Het wordt pas vanaf december 2017 mogelijk om fooien te geven via de Uber app, deze brengen maximaal gemiddeld $€ 0,57$ op per uur. Promotieopbrengsten zijn een marginaal deel van de totale bruto verdiensten (veelal niet aanwezig, maar maximaal gemiddeld $€ 0,24$ per uur). $\mathrm{X}$ en $\mathrm{Uber} \mathrm{X}$ is dan ook de grootste bron van

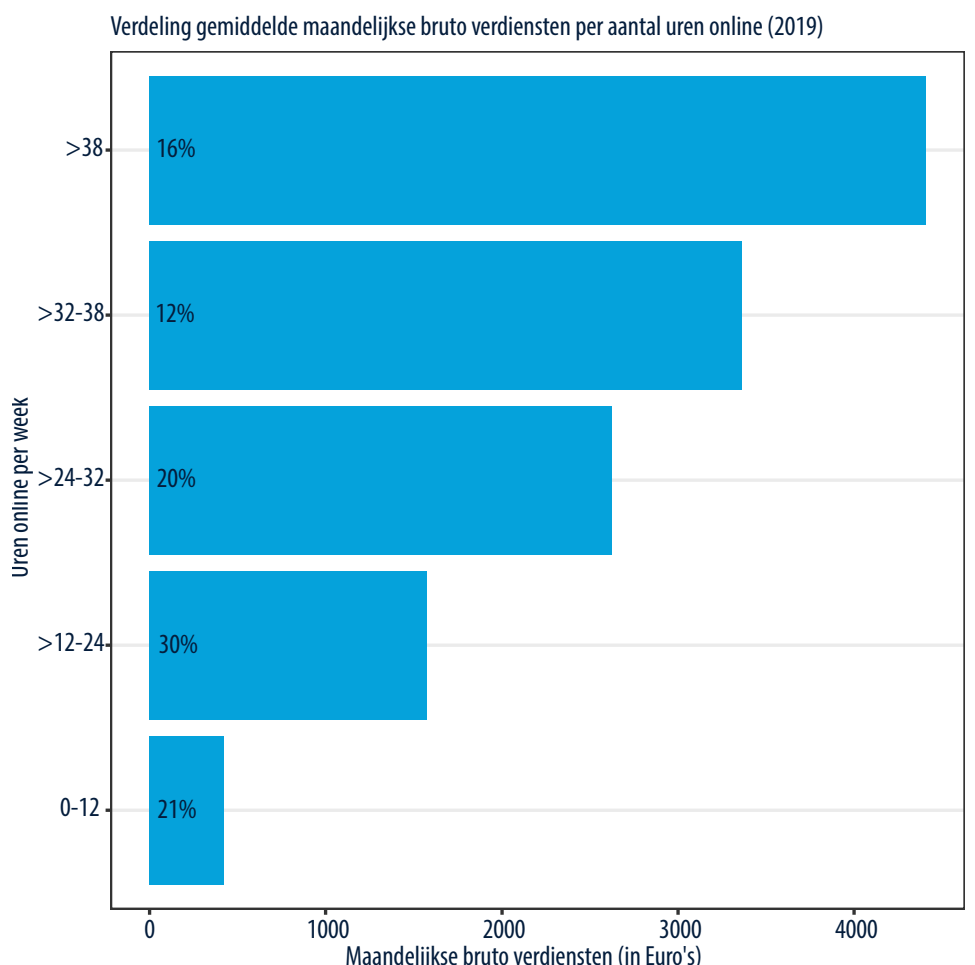

Verschillen in bruto verdiensten

- In 2019 verdiende een kwart van de chauffeurs minder dan $€ 20,69$ per uur, en een kwart verdiende meer dan $€ 28,69$ per uur.

- De bruto verdiensten per uur zijn het hoogst als men meer in de vroege ochtend of het weekend rijdt. In 2019, $10 \%$ meer ritten op die momenten gaat gepaard met ruim $3 \%$ hogere verdiensten per uur vergeleken met ritten in de middag door de week.

Ook ritten in de avond en 's nachts leveren meer op: 10\% meer ritten op die momenten gaat gepaard met, respectievelijk, $1,3 \%$ en 1,9\% hogere verdiensten per uur vergeleken met ritten in de middag door de week.

- In 2019 kreeg 90\% van de chauffeurs een fooi van gemiddeld 30 cent per trip. Een extra punt op de rating van de klant vergroot de kans op een fooi met $7 \%$.
- De bruto verdiensten per maand verschillen naar gelang het aantal uren online. Ongeveer een op de vijf gebruikers van de Uber app doet dit voor gemiddeld 12 uur per week of minder. Hiermee verdienen zij ongeveer $\in 420$ in de mand. $30 \%$ van de chauffeurs gebruikt de app tussen de 12 en and 24.574 per mand. $28 \%$ van de chaufeurs is 32 ur 1.574 per maand. $28 \%$ van de chauffeurs is 32 uur per week of meer online. Wie 32 tot 38 uur online is verdient gemiddeld $€ 3.365$ bruto per maand. Wie gemiddeld meer dan 38 uur per week online is verdient gemiddeld $€ 4.409$ bruto per maand.

- Een chauffeur die 40 uur per week zou werken in 2019, tegen verdiensten van $€ 24,48$ per uur, zou gemiddeld $€ 4.240$ bruto verdienen per maand.

- Chauffeurs die weinig online zijn op de Uber-app vullen waarschijnlijk hun maandinkomen aan met andere activiteiten (bijvoorbeeld als zelfstandig chauffeur of chauffeur bij een taxibedrijf).

- Chauffeurs kunnen dus hun verdiensten opkrikken door meer uren online te zijn: 1 uur online extra in de week voor Uber X gaat gepaard met 5\% hogere verdiensten in die week.

- Chauffeurs kunnen ook meer verdienen door een hogere acceptance rate: gegeven het aantal uren dat zij online zijn, een $10 \%$ hogere acceptance rate in de week gaat gepaard met een ongeveer $2 \%$ meer bruto verdiensten in die week. 


\section{Uber Amsterdam: Gebruikers Uber-app, gemaakte trips en verdiensten 2016-2019 Factsheet}

\section{Verantwoording}

In opdracht van Uber Amsterdam doet het Researchcentrum voor Onderwijs en Arbeidsmarkt onderzoek naar de 1) werktijden en verdiensten van chauffeurs die de Uber app gebruiken en fluctuaties in de tijd, 2) motieven om als chauffeur voor Uber te werken en 3 ) de gevolgen van positieve of negatieve startmotieven voor de kwaliteit van het werk. Deze Factsheet maakt gebruik van data uit de administratie van Uber voor de periode 2016-2019 om antwoord te geven op de eerste vraag.

\section{Definities}

Chauffeurs: De data in deze Factsheet heeft betrekking op alle chauffeurs die ooit in hun tijd via Uber minstens 4 ritten in 1 maand in Amsterdam hebben gereden. In deze Factsheet hebben wij gebruik gemaakt van alle data voor elke week waarin een chauffeur minstens 1 rit in Amsterdam heeft gereden. Deze definitie is ruimer dan de definitie die Uber in afspraak met Gemeente Amsterdam hanteert (te weten: minstens 4 ritten in Amsterdam in één maand).

Tijd online: De totale tijd die chauffeurs die de Uber-app gebruiken (tijd online) is opgedeeld in minuten beschikbaar (wachten op potentiele klanten) en minuten actief bezig zijn met trips (dat wil zeggen en route of op trip).

Acceptance rate: Het percentage van de aangeboden ritten dat de chauffeur accepteert.

Cancellation rate: Het percentage van de geaccepteerde ritten die de chauffeur cancelt (minus de eventuele ritten die gecanceld zijn door de klant).

Surged trips: Bij drukte (een grotere vraag naar ritten dan beschikbaar aanbod) kan een surge-multiplier worden gehanteerd. Dan worden ritten duurder waardoor chauffeurs meer kunnen verdienen.

Bruto verdiensten: De bruto verdiensten van chauffeurs die de Uber app gebruiken bestaan uit drie componenten: verdiensten uit trips, promotie vanuit Uber en fooien van de klanten. Uber rekent chauffeurs over de inkomsten uit trips een service feevan (onger) $25 \%$ (en da for verdiensten naftrek van de

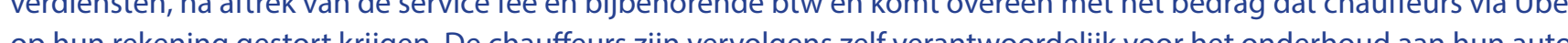
op hun rekening gestort krijgen. De chauffeurs zijn vervolgens zelf verantwo Denzinekosten, verzekeringen, inkomstenbelastingen vizovoorts.

Deze brutoverdiensten zijngecorrigeerd voor inflatie.

Wanneer wordt gesproken over bruto verdiensten per uur (of maand), betreft dit de bruto verdiensten per uur online (of per maand naar het totale aantal uren online). 


\section{Colofon}

() Researchcentrum voor Onderwijs en Arbeidsmarkt Niets uit deze uitgave mag op enige manier worden verveelvoudigd zonder voorafgaande schriftelijke toestemming van de directeur van het ROA.

\section{Researchcentrum voor Onderwijs en Arbeidsmarkt}

Maastricht University

School of Business and Economics

secretary-roa-sbe@maastrichtuniversity.nl

www.roa.nl

\section{Vormgeving}

ROA secretariaat, Maastricht

\section{september 2020}

ISSN: $2667-0488$ 